\title{
(1)
}

\section{ENTREVISTA COM CARLOS REIS}

Angélica Maria Santana Batista Luciana Morais da Silva

Recebido em 29 ago 2016. Aprovado em 14 set 2016.
Angélica Maria Santana Batista - Atualmente está no Doutorado em Literatura Comparada na UERJ e é professora da Faculdade de Formação de Professores (FFP - UERJ) no Departamento de Letras. Mestre em Literatura Portuguesa na Universidade do Estado do Rio de Janeiro; Especialista em Estudos Literários e graduada em Letras/ Português - Literaturas também pela UERJ. Tem experiência na área de editoração de textos, com ênfase em Linguística, Letras e Artes, atuando principalmente nos seguintes temas: teoria literária, comparatismos, estudos da narrativa, teoria dos gêneros literários, literatura brasileira contemporânea, literatura portuguesa contemporânea, literatura galega contemporânea e literatura infanto-juvenil com artigos publicados nas referentes áreas. Participa do diretório de grupo de pesquisa do CNPq "Estudos Literários: outras linguagens; outros discursos". Participa como delegada suplente da Comissão Técnica Nacional de Diversidade para Assuntos Relacionados à Educação dos Afro-brasileiros (CADARA) e atua como educadora social em ONGs e eventos envolvendo a exaltação da negritude.

Luciana Morais da Silva é Doutoranda em Literatura Comparada pela Universidade do Estado do Rio de Janeiro (UERJ), Brasil, sob a orientação do Professor 
Doutor Flavio García, e Doutoranda em regime de cotutela da Universidade de Coimbra (UC), Portugal, sob a orientação do Professor Doutor Carlos Reis. É Licenciada em Português - Literaturas pela Faculdade de Formação de Professores (FFP) da UERJ; Mestre em Letras (Literatura Portuguesa) pela UERJ, Brasil (2012), e em Letras Vernáculas (Literaturas Africanas de Língua Portuguesa) pela Universidade Federal do Rio de Janeiro (UFRJ), Brasil (2012). Dentre os títulos que vem publicando, sejam como trabalhos completos em anais de eventos, artigos completos em periódicos, capítulos de livro ou livro, ressalte-se Novas Insólitas Veredas: leitura de A varanda do Frangipani, de Mia Couto, pelas sendas do Fantástico (Rio de Janeiro: Dialogarts, 2013). Link de acesso ao CV_Lattes: http:// lattes.cnpq.br/2847441618182578. 


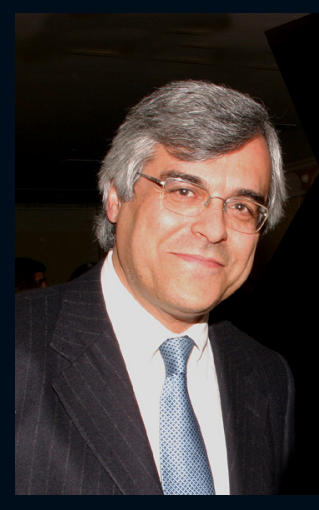

Carlos (António Alves dos) Reis é professor catedrático na Faculdade de Letras da Universidade de Coimbra (FLUC), Portugal, onde dirige o Centro de Literatura Portuguesa (CLP) e, no seio das atividades do CLP, coordena o projeto de pesquisa "Figuras da Ficção". Na FLUC, leciona Literatura Portuguesa e Teoria da Literatura, tanto em nível de graduação, quanto de pós-graduação, orientando pesquisas de mestrado, doutorado e pós-doutorado, de estudiosos portugueses ou estrangeiros que ali vão, oriundos de diferentes partes do mundo, mas, em sua grande maioria, idos do Brasil. Além disso, o Professor Doutor Carlos Reis tem atuado, mundo afora, como professor visitante convidado de universidades espanholas, norte-americanas e brasileiras, por exemplo. Em 2014, ele esteve na UERJ, com bolsa da Escola de Altos Estudos da CAPES, lecionando no Programa de Pós-Graduação em Letras, proferindo conferências e palestras como as que apresentou a título de aula inaugural do semestre letivo -, ministrando workshops e participando de eventos acadêmicos. Nesse ano, integrou a mesa de conferências de abertura do II Congresso Internacional Vertentes do Insólito Ficcional, já tendo estado na mesa de conferências da abertura na primeira edição desse mesmo Congresso em 2012. Agora, em 2016, retorna para a mesa de conferências da abertura do III Congresso Internacional, consolidando suas passagens, não mais insólitas, por essa área de estudos e pesquisas sobre o insólito. Recentemente, no bojo das ações previstas no Plano de Trabalho do Acordo de Cooperação Interinstitucional firmado entre a UERJ e a UC, o Professor Doutor Carlos Reis supervisionou o Estágio Sênior de Pesquisa de um docente da UERJ e coorientou uma doutoranda da UERJ, cujo processo se converteu em cotutela, ora já em fase conclusiva. Seus laços com o Brasil, o Rio de Janeiro e a UERJ têm se feito notar de diferentes maneiras. 
P.: O Professor se notabilizou, ao largo de seus estudos queirosianos, pela publicação do Dicionário de narratologia, em parceria com Ana Cristina Lopes (Almedina, 1998), e, nas últimas décadas, vem, no seio dos estudos da personagem, com o já consagrado projeto de pesquisa "Figuras da Ficção", retornando à narratologia, em sua fase contemporânea, por si identificada como Estudos Narrativos. Esse percurso o fez sintetizar muitos termos-conceito e mapear certos eixos-chave de articulação dos mundos possíveis narrativos, em que se sustentam as discussões em torno dos elementos de composição textual - personagens, tempo, espaço, ação... Pensando nos mundos possíveis ficcionais, que termos-conceito e eixos-chave dos estudos narrativos seriam essenciais para os estudos das relações entre "mundos realistas" e "mundos insólitos"?

R.: No quadro da pesquisa que tenho levado a cabo, dou cada vez mais valor à noção de figuração. Não se trata de, com essa noção, encontrar uma designação alternativa para o termo, mais convencional, caracterização; pela forma como encaro aquele conceito, ele implica não apenas os procedimentos construtivos da personagem como tal, mas também a sua condição de entidade ficcional. O desafio interessante será indagar que procedimentos de figuração distinguem a personagem dos mundos realistas da personagem dos mundos insólitos. Um bom programa de pesquisa!

P.: O Professor consideraria, conforme certas parcelas da teoria dos mundos possíveis vêm discutindo, que os mundos possíveis ficcionais seriam mundos acessíveis por suas conexões com um mundo real empírico, no qual o mundo ficcional iria buscar 
referências? Recuperando o que se tem dito sobre a questão, e centralizando a importância da personagem, como o senhor explicaria essas relações?

R.: Entendo que a separação drástica dos mundos possíveis ficcionais em relação ao mundo real empírico seria uma mutilação do "diálogo" multissecular que ficção e real vêm mantendo. E que desde Aristóteles está contemplada em incontáveis textos teóricos. Nesse sentido, tento aprofundar a noção lotmaniana de modelização secundária (que sempre me pareceu e continua a parecer extremamente fecunda) e conceber uma modelização ficcional como construção de linguagem que se resolve na construção de modelos de mundo submetidos à lógica da ficcionalidade. De acordo com essa lógica (seja ela de teor contratualista ou de feição essencialista), a personagem é sempre suscetivel de remeter para o real que, pelo impulso da ficção, é modelizado em segunda instância.

P.: Desde o princípio desta nossa conversa, apontamos para duas distintas e, mesmo, opositivas arquiteturas de mundos possíveis ficcionais - uma realista, outra insólita. No universo das teorias acerca dos mundos possíveis de ficção, uma das questões mais centrais envolve o conceito de mimeses, separando um conjunto de ficção mimética de outro, cuja ficção seria não mimética. Não há, todavia, consenso sobre essa divisão, já que alguns teorizadores defendem que a mimeses é uma condição inerente e necessária a toda e qualquer ficção. O que distinguiria uma arquitetura de outras seria, de fato, os processos de verossimilhança empregados na sua armação. Tomando por polos comparativos a ficção tida por realista e a tida por 
fantástica, lato sensu, como o Professor veria, em cada uma dessas estruturas, a questão da mimeses e a da verossimilhança?

R.: Mesmo considerando a ficção mais radicalmente fantástica, tenho dificuldade em considerar que ela se encontra totalmente alheada das ficções ditas realistas, até pelas ligações que sempre podemos estabelecer entre o fantástico e as nossas experiências empíricas. Através de diversos processos retóricos (hipérboles, desfigurações zoomórficas, configurações de seres sobrenaturais, construção de atmosferas desrealizadas, etc.), o fantástico só fará sentido desde que, mesmo que remota e enviesadamente, formos capazes de ler nele movimentos de alusão ao real. Nesse sentido, as ficções realistas podem ser um marco que o fantástico, mesmo não se lhe referindo explicitamente, procura subverter. Ele pode cancelar a verossimilhança que a ficção realista cultiva, mas não anula a mimese.

P.: Os mundos possíveis ficcionais, se fantásticos ou com nuances diversas do insólito, poderiam ser considerados não miméticos? Ou seriam mundos miméticos construídos com mecanismos discursivos que causam efeitos próprios da manifestação do insólito? Se sim, quais seriam os mecanismos mais comuns?

R.: Conforme antes disse, tenho dificuldade em aceitar um conceito de mimese que se limite à representação de objetos e de pessoas "tangíveis", deixando como irrepresentável o mundo dos afetos, dos valores, dos sentimentos e das ideias. Aquilo, em suma, que também designamos como mundos epistémicos. Isto aplica-se, a meu ver, à mimese que se resolve 
na configuração do fantástico e no insólito. O que antes chamei processos retóricos compreende um leque alargado de dispositivos difíceis certamente de sistematizar, no estado atual do conhecimento.

P.: Em seu projeto de pesquisa "Figuras da Ficção", dentre os aspectos que têm merecido destaque, vêm-se sobrelevando a transficcionalidade midiática. Tal seria resultado tanto do cinema, quanto da televisão e, mais contemporaneamente, do ciberespaço, e, em parte, da multi e transmidialidade que hoje se experimenta. Disso resultaria a sobrevida das personagens, não mais apenas na literatura em si, mas em trânsito de um media para outros. Assim, com olhar mais atento à ficção fantástica - ou insólita, como mais abrangente -, como o senhor comentaria esse fenômeno? Pensemos no cinema, na televisão e no ciberespaço, em especial.

R.: A noção de sobrevida da personagem, que decorre dos conceitos de figura e de figuração, encerra um considerável potencial heurístico. Mas esse potencial só se concretiza se formos capazes de apreender a dinâmica da personagem que a leva a transcender as "fronteiras" da ficção em que ela parecia estar "encerrada". Novas refigurações - na literatura ou, mais sugestivamente, nas artes da imagem - asseguram à personagem uma sobrevida que garante a sua permanência para além do tempo e do espaço em que ela surgiu. E se a personagem aparentemente "encerrada" numa determinada moldura ficcional pode ir além dessa moldura, então a sobrevida pode revestir as feições do insólito. 
P.: O projeto do Dicionário de Personagens da Ficção Portuguesa já é uma realidade, esperando apenas sua materialização em um site acessivel pela web. Quais seriam as expectativas do Professor para a efetivação do projeto e seus prováveis desdobramentos após escolha e fixação das personagens que comporão o escopo de verbetes?

R.: No momento em que respondo a esta questão, o Dicionário está já online e disponível, no endereço http://dp.uc.pt/. Trata-se de uma versão de arranque, que compreende, como ponto de partida, 30 personagens. A estas juntar-se-ão muitas outras: cerca de 20 até ao final deste ano e um total de cerca de 200 , nos próximos dois anos. O crescimento do Dicionário depende da disponibilidade de trabalho dos colaboradores e da incorporação de novos colaboradores, também no Brasil.

P.: Voltando ao percurso pelos media digitais mencionados, qual o futuro do Dicionário de Personagens da Ficção Portuguesa?

R.: Desejavelmente, as manifestações da personagem em media digitais (por exemplo, nos videogames) serão contempladas pelo Dicionário, sempre que essa manifestação derive, em movimentos de sobrevida, de personagens literárias.

P.: No projeto "Figuras da Ficção", o Professor construiu, em conjunto com outros pesquisadores, marcas a serem seguidas para a dicionarização da personagem ou processos que possibilitariam a plena análise dos traços compositivos da personagem. Assim, diante da singularidade de composição de personagens, o que tornaria uma personagem passível de pertencer ao Dicionário de Personagens da Ficção? 
R.: A escolha nem sempre é fácil, mas é viável. O grupo de pesquisa que coordeno responde a solicitações minhas e opera, por assim dizer, em abordagens por círculos concêntricos. Partimos dos ficcionistas e personagens óbvios, para aqueles que o são menos; e alargamos sucessivamente o campo de procura. Por exemplo, e olhando o século XIX: Eça, Garrett, Herculano, Júlio Dinis e Camilo são óbvios; António Pedro Lopes de Mendonça, Abel Botelho e Júlio Lourenço Pinto estão num segundo plano, Bulhão Pato e Manuel Maria Rodrigues são discutiveis. E assim por diante. Uma espécie de critério supletivo: damos atenção a romances de personagem. Por exemplo, Mário, de Silva Gaio. Por fim: não é fácil e pode ser problemático tomar decisões, mas pior do que isso será sempre não as tomar.

P.: Em busca de esclarecer ainda mais os questionamentos em torno dos processos de figuração de personagens, hoje marcados pela multi-representatividade, se é que podemos assim nomear, nos vários media, como se daria, de modo mais sistemático, em uma personagem de matiz fantástico, a sua composição? Haveria traços típicos ou antitípicos de uma personagem de composição insólita?

R.: É difícil responder de uma forma taxativa, até porque para lá chegarmos necessitamos, talvez, de uma pesquisa autónoma. No meu livro Pessoas de Livro, tento descrever alguns dispositivos que frequentemente (mas não obrigatoriamente de forma simultânea) encontramos na figuração das personagens. Considero essa tentativa uma primeira e ainda incompleta abordagem. O desenvolvimento da conceptualização da figuração, no quadro do fantástico, implica que tenhamos em conta, até onde isso é 
possível, as estratégias discursivas e os componentes semânticopragmáticos que o definem. E isto, tanto quanto possível, com recurso a "casos de estudo" transnacionais. Em suma: um bom tema de pesquisa para doutorado.

P.: Toda leitura é precária, visto que é um processo contínuo de preenchimento de pontos indeterminados (ou vazios) orquestrados na e pela cisão entre o escrito e o imaginado. Pensando especificamente no que o senhor chamou de "civilização da imagem", podemos afirmar que a era digital, com a emergência de novos media e outras possibilidades mais dinâmicas de representação das personagens, diminuiu ou esgarçou tais pontos?

R.: Por coincidência, neste momento estou a escrever uma conferência, para um colóquio na Alemanha, cujo título é "Character: a concept that does not stand still". A ideia é observar e tentar entender, em narrativas como as dos videogames ou as da chamada (genericamente) narrativa digital, como a personagem sobrevive, como se renova e como convoca procedimentos interativos, por parte do jogador e do leitor (se é que ainda podemos chamar-lhe assim). Curiosamente, essa "dinamização" da personagem encontra-se já em projeto em textos oitocentistas de autores como Garrett ou Machado de Assis. E por certo também de outros. O problema é que eles não dispunham de ferramentas informáticas nem sabiam programação... Por outro lado, a vantagem é que nos legaram (eles e muitos outros) personagens que, a meu ver, nenhuma narrativa digital, pelo menos por agora, é capaz de igualar. 
P.: Ao lado das reflexões sobre os processos de figuração da personagem, o Professor tem, também, estudado o cânone. Quais as implicações do estudo do cânone para a fixação da personagem? Personagens com mecanismos estruturais mais bem engendrados participariam de narrativas canônicas? Por quê?

R.: A questão do cânone é, hoje em dia, uma questão fundamental. Se as obras (as narrativas, em particular) do cânone nos tocam pelo lado de uma representatividade cultural, histórica e linguística, com forte marca identitária, então há personagens que participam nesse processo de representação e nos seus desenvolvimentos formativos e que têm de ser valorizadas. Por exemplo: Vasco da Gama ou Nuno Álvares, n'Os Lusíadas, Afonso da Maia, n'Os Maias, Blimunda, em Memorial do Convento. E muitos outros. Elas são elementos com grande relevância semântica, em universos ficcionais com a marca identitária a que me referi.

P.: Em seus escritos, há preocupações com os dispositivos de ficcionalização e as fronteiras da ficção, com base na metalepse. Pensando nessa figura, como refletir a figuração na contemporaneidade, considerando-se os dispositivos composicionais?

R.: A metalepse é hoje um conceito decisivo, recuperado da retórica para os estudos narrativos. Justamente: ela ilumina questões delicadas como a da comunicação e interpenetração de mundos autónomos. Quando "convivemos" com personagens ficcionais (e isso acontece muito mais frequentemente do que pensamos), acabamos por reconhecer: não estamos sós. Ou 
então: é para isto que lemos romances. A metalepse é um conceito operatório importante, para percebermos os matizes e as várias modalidades do movimento transficcional e até transliterário das personagens, às vezes apoiado em reflexões metaficcionais que a própria narrativa incorpora.

P.: Ampliando a questão anterior, como pensar, nesse mesmo norte, nos procedimentos que levam à sobrevida das personagens?

R.: Mais do que em procedimentos, é necessário pensar desde já no próprio conceito de sobrevida, que considero ainda em fase de consolidação. Para além disso, é possível antecipar que um terreno muito fecundo (e que conta já com apreciáveis contributos, no plano teórico e não só nesse; lembro os trabalhos de Marie Laure Ryan) para o desenvolvimento daquela noção é o conhecimento das várias linguagens, em diversos contextos mediáticos, que incorporam e recontextualizam a personagem. Estamos aqui no campo das relações intermediáticas e dos efeitos de refiguração que, naqueles outros contextos mediáticos, fazem "sobreviver" a personagem. Mas não só isso. A personagem em processo de sobrevida transmediática é já outra e está sujeita a condicionamentos que interferem naquele processo. Por exemplo: recentemente, tive oportunidade de abordar a sobrevida e a refiguração da personagem James Bond, que migrou da literatura para o cinema e que, nessa migração, passou, antes de tudo o mais, por opções de casting que, aliás, continuam em aberto. Já se falou na possibilidade de um James Bond feminino - que se chamaria Jane Bond e que teria, evidentemente, os seus "Bond boys"... 
P.: O Professor publicou alguns ensaios sobre o insólito ficcional abordando a projeção de figuras de conformações irracionais ou desconexas. Para o senhor, a armação de mundos possíveis do insólito representaria, como processo discursivo-textual, uma prática retórica que ferisse o ethos da verossimilhança realista?

R.: Se o insólito for "absorvido" pela verossimilhança realista, perde sentido. De certa forma, ele surge e é acolhido porque a verossimilhança realista, para alguns ficcionistas e para muitos leitores, deixou de fazer sentido. E esse esgotamento tem marcas de épocas e de valores sujeitos à erosão imparável da História.

P.: Escrevendo a respeito do herói desportivo, o senhor se refere à biografia do herói não apenas como uma narração dos feitos do biografado, mas, também, como a reatualização de imagens caras ao meio publicitário. Sabemos que a autobiografia é muito presente na literatura contemporânea, desvelando as (des)fronteiras entre o ficcional e o fatual, com recurso a mecanismos diferenciados (artigos de jornal, reportagens, fotografias, retratos, documentos em geral) como mecanismos de reinvenção do experimentalismo verbo-expressivo na prosa. Ao refletir sobre a importância dessas estratégias, como considera que se possa compor um estudo que abarque as novas tendências do discurso literário?

R.: Esse estudo é possível e é pertinente se conseguirmos superar dois condicionamentos (pelo menos). Um: a ideia de que a literatura está encerrada num campo incomunicável com o exterior, o que considero absurdo (ainda recentemente, muitas 
pessoas que contestaram a atribuição do prémio Nobel da Literatura a Bob Dylan não se deram conta desse absurdo...). Outro: o de que certas correntes de estudo, como é o caso dos Estudos Culturais, têm vindo a pôr em causa, na academia e fora dela, uma visão puramente canónica, na aceção mais conservadora do termo, da literatura e das práticas culturais em geral. Mas, atenção: uma opção metodológica como esta falhará, se Ihe faltar critério, rigor conceptual, pesquisa documental adequada e tudo o mais que dá credibilidade a uma pesquisa. Não se trata apenas de substituir Camões e Shakespeare por Elvis Presley e pela telenovela...

P.: Tanto a pessoa física Carlos Reis, quanto o projeto de pesquisa "Figuras da ficção", que o senhor coordena, têm blog e página no Facebook, em que se publicam notícias e textos teóricos ou críticos. Qual a importância desses media na divulgação de ideias na atualidade globalizada do aqui e agora?

R.: Considero-a fundamental e decisiva. Mas é preciso tratar essas ferramentas e contextos de trabalho de acordo com as suas regras próprias (que são regras de linguagem) e com a consciência de que o seu alcance é assustadoramente imenso.

P.: Que recados o Professor deixa aqui para os estudiosos da narrativa e, em especial, das personagens, com destaque para a tensão opositiva em modelos de mundos possíveis realistas e insólitos?

R.: Recado não direi. Prefiro dizer sugestão: a de que aquela tensão opositiva não é um conflito, mas um desafio com múltiplas vias de desenvolvimento possíveis. 
P.: O que não nos lembramos de lhe perguntar, mas o senhor gostaria de nos ter respondido?

R.: Perguntaram muito, perguntaram bem e perguntaram até mais do que eu pude responder... 